\section{Drivers for Teleconsultation Acceptance in Brazil: Patients' Perspective during the COVID-19 Pandemic}

\author{
Fatores para a Adoção da Teleconsulta no Brasil: Análise na Perspectiva \\ dos Pacientes Durante a Pandemia de COVID-19
}

\author{
Marcus Rodrigues Peixoto*1 $\odot$ \\ Jorge Brantes Ferreira ${ }^{10}$ \\ Laís Oliveira $^{1}$ 일
}

\section{ABSTRACT}

Context: teleconsultation can be a strategic technological tool for patients to access quality healthcare while dealing with resource challenges within health industry. It can be particularly relevant during and after the COVID-19 pandemic, when the social distancing world had to scramble for new technological solutions to offer quality healthcare services with reduced personal contact. Objective: our research proposes an integrative technology acceptance model to evaluate the drivers of teleconsultation adoption by patients, aligning constructs from the technology acceptance model with other drivers, such as technology readiness, trust, and selfefficacy. Methods: analyses included descriptive statistics and structural equations modeling based on survey's data from a sample of 415 consumers. Results: results indicate significant relationships between the assessed constructs, with particular relevance on the effects of perceived usefulness, anteceded by trust and technology readiness, on attitude and intention to use teleconsultation. Conclusion: our findings provide helpful insights for health organizations and regulators associated with the diffusion of teleconsultation. The study findings also indicate that the challenging COVID-19 pandemic context may be affecting patients' intention to adopt teleconsultation.

Keywords: teleconsultation; telemedicine; technology acceptance; trust; technology readiness; healthcare innovation.
* Corresponding Author.

1. Pontifícia Universidade Católica do Rio de Janeiro, IAG Business School, Rio de Janeiro, RJ, Brazil.

Cite as: Peixoto, M. R., Ferreira, J. B., \& Oliveira, L. (2022). Drivers for teleconsultation acceptance in Brazil: Patients' perspective during the COVID-19 pandemic. Revista de Administração Contemporânea, 26(2), e210063. https://doi.org/10.1590/1982-7849rac2022210063.en

\section{RESUMO}

Contexto: a teleconsulta, como ferramenta tecnológica, pode gerar maior acessibilidade a serviços de saúde de qualidade, além de servir para lidar com os desafios de recursos na indústria da saúde. Pode também ser particularmente relevante durante a pandemia de COVID-19, com o distanciamento social que demanda novas soluçóes tecnológicas para a oferta de serviços de qualidade com contato pessoal reduzido. Objetivo: o artigo propóe um modelo integrativo de aceitação de tecnologia para avaliar os fatores determinantes da adoçáo de teleconsulta pelos pacientes, alinhando construtos oriundos do modelo de aceitaçáo de tecnologia com outros construtos, como prontidão tecnológica, confiança e autoeficácia. Métodos: uso de análises descritivas e modelagem de equaçóes estruturais com dados dos questionários de 415 consumidores. Resultados: indicam relaçóes significativas entre os construtos avaliados, com particular relevância nos efeitos da utilidade percebida, antecedida pela confiança e prontidáo tecnológica, sobre atitude e intenção de uso da teleconsulta. Conclusão: os resultados fornecem achados úteis para organizaçóes de saúde e reguladores públicos sobre a difusáo da teleconsulta, indicando que o contexto desafiador da pandemia de COVID-19 pode estar impactando a intenção dos pacientes de adotar a teleconsulta no Brasil.

Palavras-chave: teleconsulta; telemedicina; adoção de tecnologia; confiança; prontidão tecnológica; inovação na saúde.
JEL Code: M31, O33, 11

Editors-in-chief: Wesley Mendes-Da-Silva (Fundação Getulio Vargas, EAESP, Brazil) 미 Marcelo de Souza Bispo (Universidade Federal da Paraíba, PPGA, Brazil) (c) Associate Editor: Emílio José M. Arruda Filho (Universidade da Amazônia, Brazil) (C) Reviewers: Ricardo Limongi (Universidade Federal de Goiás, FACE, Brazil) (c) Élcio E. de Paula Santana (Universidade Federal de Uberlândia, FAGEN, Brazil) Peer Review Report: The Peer Review Report is available at this external URL. Received: February 10, 2021 Last version received: May 13, 202 Accepted: May 18, 2021

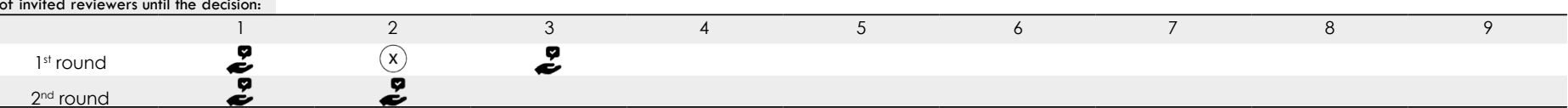




\section{INTRODUCTION}

Providing efficient access to health services can cause a positive social impact by addressing issues such as health and social inequalities (Kayser et al., 2019) and population aging (Dario et al., 2016). Improvements in health services regarding quality, costs (Gonçalves et al., 2019), and access (Fanta \& Pretorius, 2018) could be achieved through information and communication technologies (ICT) (Jones, Rudin, Perry, \& Shekelle, 2014). Moreover, telehealth - i.e., the use of ICT in health services becomes more relevant when patients experience reduced mobility, such as the need for social distancing during the COVID-19 pandemic (Smith et al., 2020). Many studies have already shown telehealth's significant potential to enhance healthcare practices (Yeo, Al-Ashwal, Handayani, \& Lee, 2019), particularly during the COVID-19 pandemic (Scott \& Mars, 2020). Despite the importance of ICT in consumers' health-related services, it is still necessary to improve the understanding of its acceptance and diffusion, identifying relevant factors that can influence the acceptance of innovative technologies in health services (Kayser et al., 2018).

This study seeks, therefore, to investigate drivers of user acceptance of a technological health service (teleconsultation) in order to contribute to a better understanding of consumer's intention in adopting technology innovations. Our study's purpose gains even more importance due to some relevant gaps found currently in the debate on telehealth's acceptance, having areas that need further conceptual development.

First, a broader understanding of telehealth's acceptance from a patient perspective is required (Tao et al., 2020). Telehealth's acceptance can be assessed by different domains or perspectives, including patient, healthcare provider (e.g., practitioner), organization (e.g., hospitals), and the public domain in community-related studies (Jennett et al., 2003). Such perspectives can generate distinct strategies and results of technology acceptance among different user groups (Chauhan \& Jaiswal, 2017). However, a significant share of academic research has focused solely on healthcare providers or organizations to explain telehealth services' acceptance (Holden \& Karsh, 2010; Sligo, Gauld, Roberts, \& Villa, 2017; Tao et al., 2020).

Moreover, studies based on the patient perspective of telehealth's acceptance usually do not include technologyrelated factors in their conceptual proposals. Or and Karsh (2009) analyzed 94 studies that dealt with consumer health information technology (CHIT) acceptance from a patient's perspective. However, their findings suggested a low presence of technology-related factors in such studies, creating potential gaps for the comprehension of patients' acceptance of technology-driven health services (Fanta \& Pretorius, 2018; Yosser et al., 2020) since such services portray important technological content.

In addition, all potential factors that can influence the patients' acceptance of technological innovation in health services still provoke debates. Although the technology acceptance model (TAM) has been the most used framework to explain end-users' acceptance of CHIT empirically, further research of potential factors that enhance TAM's framework in telehealth adoption settings is still needed (Tao et al., 2020), including the adoption of factors associated with the specific characteristics of health services (Lanseng \& Andreassen, 2007; Velsen, Tabak, \& Hermens, 2017).

To address such gaps, our study proposes a theoretical model that: (a) is based on patient's dimension; (b) includes a technological perspective; (c) uses factors related to both TAM and health services' specific demands. In this regard, patients' acceptance toward telehealth or any of its related services (e.g., teleconsultation) can be linked to several antecedents. TAM has been used as one of the main frameworks in explaining the drivers of technology acceptance (Chauhan \& Jaiswal, 2017; Tao et al., 2020; Tsai, 2014). In the TAM, user's behavioral intention (BI) signals the closest construct to actual usage (Davis, 1989), mainly in situations when actual consumption has not happened yet. Therefore, BI will reflect users' technology acceptance in this study (Holden \& Karsh, 2010). In addition to BI, this study will include and evaluate the other three original TAM's constructs: attitude (ATT), perceived ease of use (PEOU), and perceived usefulness (PU). However, since the model was designed originally to assess user acceptance of computer technology, the inclusion of additional variables seems necessary to conform to other specific study contexts (Davis, 1993; Venkatesh, 2000). On this subject, Holden and Karsh (2010) highlight TAM's limitation regarding healthcare services and propose further studies to clarify and include healthcare specific beliefs in future models.

Regarding the healthcare industry, Lanseng and Andreassen (2007) highlighted some of the important singularities that differentiate health from other services, including the 'negative' demand propensity (i.e., consumers' are not voluntarily 'willing' to consume typical health services), the high level of stress normally associated with the consumption experience, and the high level of trust and credibility required as consumers depend on providers' capacity to deliver impactful and crucial services for their lives. Additionally, Velsen, Tabak, and Hermens (2017) point out the relevance of trust for health services, given the relationship between practitioner and patient. Moreover, based on telehealth's characteristics of partial self-servicing 
and distant contact through technological means, selfefficacy should also be included as a critical factor affecting acceptance from patients (Yun \& Park, 2010). Therefore, our study will also incorporate the constructs of trust (TRU) and self-efficacy (SE) in the assessment of patients' acceptance of telehealth.

Finally, whereas Venkatesh and Davis (1996) proposed the search for antecedents of perceived ease of use and perceived usefulness, Parasuraman (2000) examined the reasons to understand increased customers' frustration with technological items consumption through assessing their technology readiness (TR). In this sense, patients' technology readiness may be another critical success factor to explain the acceptance of telehealth services (Holt et al., 2019; Kayser et al., 2019).

From an academic perspective of telehealth's acceptance, Tao et al.'s (2020) literature review depicted the use of diverse models applied empirically to investigate enduser's acceptance of consumer-oriented health information technologies. Although TAM is seen as the dominant model for explaining end-users' behavior, the authors suggested the extension of the model with inclusion of additional independent and moderating variables in order to cover all complexities and idiosyncrasies of health services, including trust and self-efficacy, among others. Interestingly, however, none of the identified studies tried to incorporate technology readiness, trust, self-efficacy, and the TAM's constructs all together.

Regarding managerial implications, some other current challenges also lend relevance to this research, such as: (a) the growing interest in the subject of patient involvement with healthcare solutions (Michel-Verkerke, Stegwee, \& Spil, 2015; Tavares \& Oliveira, 2016); (b) the quest to decrease investment risks and resource losses when developing and promoting healthcare technological innovations (Lanseng \& Andreassen, 2007; Mauco, Scott, \& Mars, 2019); (c) the need for a better comprehension of the potential barriers that an aging population faces when dealing with technological innovations for health services (Cimperman, Brencic, \& Trkman, 2016; Fox \& Connolly, 2018); (d) the search for a broader understanding of the potential impacts of 'exceptional situations,' such as the COVID-19 pandemic, in the demand for health technological solutions (Ouimet, Wagner, Raymond, \& Pare, 2020).

Additionally, Scott and Mars (2020) point to the resurgence of the debate about patient's readiness for telehealth as soon as the special regulatory dispensations allowed during the COVID-19 pandemic end. This scenario is more critical in countries such as Brazil, where telehealth implementation had not been regulated before the 2020 pandemic crisis and regulatory dispensations caused significant reactions from both public and private stakeholders to cope with the unexpected situation (Oliveira, Duarte, França, \& Garcia, 2020). Hence, the consequences of all implemented initiatives during the COVID-19 pandemic and stakeholders' future positioning can drastically reshape the telehealth business environment in the country, including the eventual reconfiguration of the services provided by the Brazilian public health system SUS (Caetano et al., 2020).

By proposing a novel and integrated model of distinct constructs to assess user's technology acceptance, this work advances the understanding of user's technology acceptance, mainly in the relevant and complex healthcare segment. The study also contributes for further academic debates by focusing on the patient domain, a growing concern for research in healthcare technology diffusion. Additionally, by adopting a technological perspective of the patient domain, this study adds valuable knowledge on debates about health-related technology innovations' acceptance. Finally, since our literature review did not find any evidence of similar works about the acceptance of teleconsultation in Brazil, and understanding that local and cultural aspects can impact the factors for teleconsultation adoption (Baudier, Kontradeva, Ammi, Chang, \& Schiavone, 2021), our study's contributions also gain managerial and social relevancy for the coming discussion about telehealth regulation in the country during the post-COVID-19 period.

\section{LITERATURE REVIEW}

\section{ICT in health services}

The use of information and communication technologies (ICT) in healthcare may provide several benefits for the health industry, its stakeholders, and the society at large, including gains in service quality, efficiency, cost savings, and accessibility (Cimperman et al., 2016; Gonçalves et al., 2019; Huang, 2013). Such technological improvements become more critical as challenges associated to resource constraints and aging population increase (Lanseng \& Andreassen, 2007; Rahimpour, Lovell, Celler, \& McCormick, 2008; Tsai, 2014). Additionally, potential technological improvements in health services can also decrease social inequalities, increasing its need in underdeveloped and emerging countries (Cilliers, Viljoen, \& Chinyamurindi, 2018; Fanta \& Pretorius, 2018; Mauco et al., 2019).

The definition of telehealth is still subject to debate. Adjekum, Blasimme, and Vayena (2018) describe several terms, including digital health, telehealth, and telecare, which could be interchangeably adopted to describe the use of ICT in health care services to promote general 
improvements. Velsen et al. (2017) describe telemedicine as health services with significant ICT presence. The main goal of such services is to provide treatment and bridge the distance between patients and healthcare professionals. Telemedicine's purposes also include the provision of relief and education for patients, and it is just a part of a broader potential use for ICT in health, called telehealth (Caetano et al., 2020; Tsai, 2014). From this broader perspective, telehealth includes practical service applications of ICT in daily health activities, such as teleconsulting, telediagnosis, telemonitoring, teletraining, among others (Caetano et al., 2020). Therefore, teleconsultation is one of the potential ICT services in telehealth. In this regard, the present study adopts the literature that categorizes teleconsultation as medical appointments through ICT means, including video-chat, mobile phone, or any ICT remote solution that enables the communication and interaction between healthcare providers and patients (Caetano et al., 2020; Velsen et al., 2017).

In Brazil, teleconsultation was not allowed by the country's Federal Council of Medicine (CFM) until April 2020. Before April, CFM's resolutions required medical professionals to physically examine patients before writing prescriptions. As a consequence of the COVID-19 pandemic, teleconsultation was exceptionally authorized through a presidential sanction, and its validity depends on the duration of the pandemic crisis (Caetano et al., 2020).

Finally, the potential positive impacts of technological solution in health care from a patients' perspective should be highlighted. Teleconsultation's positive influence on the lives and wellbeing of patients of distinct pathologies, such as diabetes (Dixon et al., 2020) and asthma (Portnoy, Waller, \& Elliot, 2020), has already been proven. For instance, in a recent study with teleconsultation patients in Canada, Ouimet, Wagner, Raymond, and Pare (2020) suggested that teleconsultation's utilitarian nature, which includes its potential capacity of saving time and of providing valuable and immediate health care access, has already affected positively patients' perception about its current and future adoption. Therefore, understanding the drivers for the adoption of teleconsultation from a patient perspective becomes one of the critical factors to release its full potential to improve patients' lives in the coming years.

\section{Technology acceptance}

Innovation acceptance is influenced by several factors. For instance, external factors, such as the urgency for relevant social solutions, increase the pressure for approvals of innovations' diffusion as well as the need for solutions from potential users (Rogers, 2003). The outbreak of pandemics and other natural disasters had already influenced the approval and introduction of teleconsultation in such circumstances (Baudier et al., 2021). Policy makers are more flexible and more receptive in allowing a broader use of technological solutions, such as teleconsultation, to face challenges imposed by COVID-19 on society and on health providers (Bashshur, Doarn, Frenk, Kvedar, \& Woolliscroft, 2020).

Additionally, innovation adoption rate may be influenced not only by its objective characteristics but also by its subjective ones, in addition to adopters' individual aspects (Rogers, 2003). TAM (Davis, 1989) is considered the basis for technology acceptance's concept, and it is currently adopted in several studies (Ferreira, Rocha, \& Silva, 2014). According to Davis' (1989) original model, technology acceptance refers to a consumer's behavioral intention (BI) to use a specific technology, which will lead to its actual use. Behavioral intention is directly influenced by consumers' attitude (ATT) toward using the technology. Attitude determinants are the cognitive responses to external stimulus based on consumers' perceptions of a technology's ease of use (PEOU) and usefulness (PU). Usefulness is also directly influenced by ease of use (Davis, 1989); Davis, Bagozzi, \& Warshaw, 1989), as shown in Figure 1.

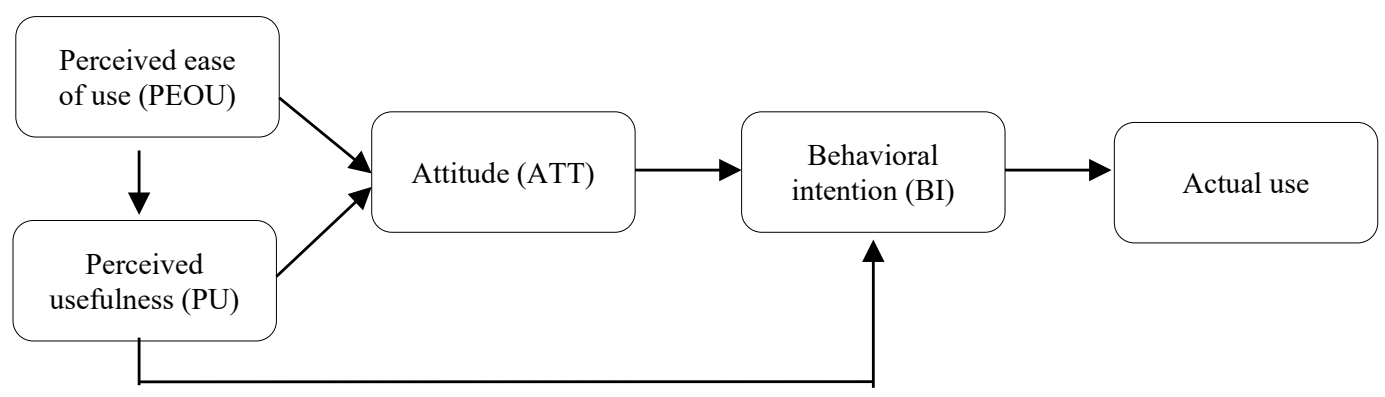

Figure 1. Illustration of technology acceptance model (TAM). 
Nonetheless, TAM's parsimony generated the need to further understand eventual additional factors that could influence user acceptance (Venkatesh, 2000). Venkatesh and Davis (1996) proposed the integration of the antecedents of TAM's cognitive factors in the model. Following works searched for inclusion of broader perspectives on technology acceptance, proposing the addition of affective (Kulviwat, Bruner, Kumar, Nasco, \& Clark, 2007; Reinares-Lara, Olarte-Pascual, Pelegrín-Borondo, \& Pino, 2016) and other non-tangible emotional aspects on consumer's technology acceptance process (Ramírez-Correa, Grandón, RamírezSantana, \& Órdenes, 2019).

Regarding health services technology, the inherent and complex nature of such services demanded deeper comprehension of factors involved in patients' technology acceptance. Hirani et al. (2017) highlighted TAM's limitations and suggested incorporating items that could address areas of telehealth use by the patient, such as accessibility, comfort, usability, security, and confidentiality. Yun and Park (2010), for instance, proposed the inclusion of two constructs, 'health consciousness' and 'perceived health risk,' into TAM's original model to evaluate consumers' search and use of disease information on internet. Similarly, Cimperman, Brencic, and Trkman (2016) introduced healthrelated variables ('doctor's opinion', 'computer anxiety,' and 'perceived security') to investigate elderly users' acceptance of home telehealth services. Finally, literature review papers focused on technology acceptance in health and healthcare suggest the need to include variables in TAM, depending on the nature of the study and its purpose (Holden \& Karsh, 2010; Or \& Karsh, 2009; Tao et al., 2020).

This study proposes a more comprehensive model to investigate patients' technology acceptance in the specific case of teleconsultation, including the complexity and specificities of health services and technologies. Therefore, our study's model includes: (a) two constructs with voluntary behavioral responses from patients, attitude (ATT) and intention to use (BI) (Davis, 1989; 1993; Davis et al., 1989); (b) two cognition reasoning constructs, perceived ease of use (PEOU) and usefulness (PU), usually associated with the acceptance of any new technological innovation (Davis, 1989; 1993; Davis et al., 1989); (c) and three other potential antecedents (Venkatesh, 2000) of such cognitive constructs. In line with the literature, these constructs include context-specific variables, i.e., constructs that hold significant relationship with health services - trust (TRU) and self-efficacy (SE) - , as well as a construct, technology readiness (TR), directly related to user's potential acceptance of technological innovations of any kind. This comprehensive set of selected constructs intents to comply with the study's purpose and to contribute with users' acceptance literature.

\section{Technology readiness}

Technology readiness (TR) refers to an individual's mental and psychological state when using new technologies. Parasuraman (2000) defines TR as "people's propensity to embrace and use new technologies for accomplishing goals in home life and work" (Parasuraman, 2000, p. 308). Consequently, it encompasses beliefs and feelings that drive individuals' (Ferreira et al., 2014) or communities' (Jennett et al., 2003) predisposition to adopt technologies.

In measuring the level of individuals' TR, Parasuraman (2000) and Parasuraman and Colby (2015) observed that consumers simultaneously presented positive and negative views about technologies. Positive views act as motivators, contributing positively to TR, whilst negative views conceive the inhibitors that diminish consumers' $T R$. The views were categorized in four dimensions: optimism and innovativeness as TR motivators, and discomfort and insecurity as TR inhibitors (Yeo et al., 2019). These dimensions reflect relative distinct behaviors that can lead, in some cases, even to paradoxical consolidated results, such as concomitant strong positive and negative feelings toward a technology by the same consumer (Parasuraman $\&$ Colby, 2015). Table 1 depicts the clear distinction among the unique characteristics of TR's dimensions.

Table 1. Technology readiness dimensions, according to Parasuraman and Colby (2015).

\begin{tabular}{lcc}
\hline TR Dimension & TR & Description \\
\hline Optimism & TR_OPT & One's positive mindset about technology in general, based on beliefs that technology could improve his/her \\
life (control, flexibility, and efficiency)
\end{tabular}


TR influences adoption rates of new technological services and products (Kuo, 2011; Lin \& Chang, 2011). Health studies suggest that understanding TR could be critical to increase the success rates of new technology (Quan et al., 2020), to avoid wasting resources, and to decrease the chances of frustrating stakeholders (Jennett et al., 2003; Yosser et al., 2020). However, literature review suggests that there is still little attention and production of empirical studies for this area and low use of reliable TR frameworks to assess end users' readiness for new health technology services (Kayser et al., 2019; Mauco et al., 2019).

Although TR refers to general beliefs regarding technology, there are intuitive relationships between TR and TAM's constructs (Ratchford \& Barnhart, 2012). Parasuraman and Colby (2015) suggest that higher TR leads to higher PEOU and $\mathrm{BI}$, and propose further studies to understand the relationships between their TR scale (Technology Readiness Index 2.0 - TRI 2.0) and TAM. The theoretical association between TR and TAM constructs was tested with various technological products and services. As suggested by Venkatesh (2000), PEOU and PU are significantly influenced by TR, as a global measure (Ferreira et al., 2014; Lin, Shih, \& Sher, 2007) or split by its four dimensions (Lam, Chiang, \& Parasuraman, 2008).

Results suggest that individuals with high levels of TR motivators (innovativeness and optimism) tend to perceive technology usefulness (PU) more easily (Lin et al., 2007).

Regarding PEOU, people with high levels of technology readiness present lower levels of discomfort and insecurity about a given technology, and can understand more easily how such technology works and how to use it (Ferreira et al., 2014).

In the health sector, a study that analyzed the adoption of mobile electronic medical records by nurses suggested that high levels of discomfort and insecurity negatively affected PEOU (Kuo, Liu, \& Ma, 2013). Lanseng and Andreassen (2007) evaluated users' readiness and attitude to predict the adoption of self-service technology in health diagnosis, and measured users' TR to select the study group, composed only of 'pioneers' (users with higher propensity for technology acceptance). The pioneers' PU and PEOU were later evaluated and the model to predict the pioneers' behavioral intention was validated. The researchers assumed, therefore, that users with higher TR would be more prone to adopt new technologies. Therefore, this study proposes:

Hypothesis 1a: Technology readiness will have a direct positive impact on patients' perceived ease of use of a technological health service (teleconsultation).

Hypothesis 1b: Technology readiness will have a direct positive impact on patients' perceived usefulness of a technological health service (teleconsultation).

\section{Self-efficacy}

From a social cognitive perspective, self-efficacy (SE) can be interpreted as a person's abstract judgments about his/her capabilities to perform a task (Tsai, 2014). From a technological perspective, SE refers to a person's self-evaluation of his/her capability of efficiently using a new technology (Compeau \& Higgins, 1995) whereas in health studies, SE represents a patient's judgment of his/her capabilities to use a telehealth system or solution (Rahimpour et al., 2008).

Venkatesh and Davis (1996) observed conceptual similarities between SE and PEOU. The authors tested their relationship empirically and found that $\mathrm{SE}$ can act as predictor of PEOU. Moreover, SE has more influence on PEOU when systems or technologies have not been experienced by users, since they tend to base their decisions on more abstract criteria (Venkatesh, 2000; Venkatesh \& Davis, 1996). This is the case in our study, considering most respondents had never experienced teleconsultation.

The link between SE and PEOU was suggested by various authors, such as Venkatesh and Davis (1996) in their study about users' perceptions of computer programs. Khalifa and Shen (2008) also found a significant relationship between SE and PEOU in a B2C mobile commerce study, and Abdullah, Ward, and Ahmed (2016) found similar results while investigating UK students' intention to adopt e-portfolios. Similar results, showing a positive and significant relationship between SE and PEOU, were found for diverse telehealth services too, such as home telecare (Rahimpour et al., 2008) and a national telehealth system (Tsai, 2014).

In this study, self-efficacy refers to patients' judgment of their ability to use teleconsultation services. Additionally, we assume that users tend to believe a new technology is easier to use depending on their judgment on their capabilities to use such technology. Thus, this study hypothesizes that:

Hypothesis 2: Self-efficacy will have a direct positive impact on patients' perceived ease of use of a technological health service (teleconsultation).

\section{Trust}

Trust reduces uncertainty (Malaquias \& Hwang, 2016) and incorporates the idea of vulnerability. People accept voluntarily to become vulnerable to others' actions in exchange for relevant personal gain, without being able to monitor or control others' actions and behaviors.

On the other hand, such trustor's willingness to be vulnerable is impacted by his/her perceptions on trustee's ability, benevolence, and integrity and is directly associated 
with a willingness to take risk (Mayer, Davis, \& Schoorman, 1995; Schoorman, Mayer, \& Davis, 2007; Velsen et al., 2017). In healthcare, the relationship between patients and healthcare providers creates an unbalance, generating the need for patients to have high levels of trust in the providers, which increases confidence risks in case of services failures (Lanseng \& Andreassen, 2007).

Velsen et al. (2017) observe that patients' willingness to rely on health services is due to health services' peculiar characteristics (e.g., high importance for the patient, sensitive personal data) and is determined by a multidimensional perspective. In the case of health technology-related services, patients' trust is the sum of trust in all factors associated with these services. For instance, data sensitivity (Cimperman et al., 2016), the complexity of the interplay between enablers and impediments (Adjekum et al., 2018), and high expectations from patients (Tsai, 2014) denote the intuitive and natural issue of trustworthiness involved in health technology-related services.

Trust can be related to PU through trustor's uncertainty regarding expected gains. The higher the consumer's trust in the vendor or the technology, the higher the perceived usefulness of such vendor or technology should be (Geffen, Karahanna, \& Straub, 2003). Tsai (2014) observed that elderly individuals' trust on healthcare providers' ability, benevolence, and integrity directly affected the expected outcomes of telehealth systems, while Lanseng and Andreassen (2007) suggested that users' trust on e-healthcare providers affected positively users' perceptions of the potential gains from using such technology. Therefore:

Hypothesis 3: Trust will have a direct positive impact on patients' perceived usefulness of a technological health service (teleconsultation).

\section{Perceived usefulness}

Perceived usefulness (PU) refers to an individual's subjective judgment and expectation about how a certain technology might improve his/her performance or outcomes for a given task, which might influence the individual's tendency to adopt it (Davis et al., 1989). In healthcare, PU is associated with patients' perceptions of benefits that the adoption of a health-related technology, such as teleconsultation, can bring to their daily lives and health conditions (Cimperman et al., 2016).

Since one's attitudes (ATT) toward a behavior are generated by strong beliefs (Davis et al., 1989; Fishbein \& Ajzen, 1975), PU, as one of these beliefs, directly and positively affects ATT. A relationship between PU and ATT was empirically tested and validated in studies with diverse technologies, including nanoimplants
(Reinares-Lara et al., 2016) and e-book readers (Ferreira et al., 2014). Similar empirical evidences were found in health technology-related services (Tao et al., 2020), such as a telecare system (Huang, 2013) and internet disease-seeking information (Yun \& Park, 2010). Consequently, this study assumes that:

Hypothesis 4a: Perceived usefulness will have a direct positive impact on patients attitude in relation to adoption of a technological health service (teleconsultation).

PU can also potentially influence consumers' intention to adopt (BI) a technology, including healthrelated technologies (Tavares \& Oliveira, 2016). Kulviwat, Bruner, Kumar, Nasco, and Clark (2007) suggest it is possible to obtain distinct or contradictory results in consumers' attitude and intentions that can be found in some technologies. Use dependency may overcome eventual negative consumer's attitude, such as mobile phones and health services. Tao et al.'s (2020) evaluation of fifty-one trials from health empirical studies on technology adoption also suggests significant influence on patients' BI. Hence,

Hypothesis 4b: Perceived usefulness will have a direct positive impact on patients' behavioral intention to use a technological health service (teleconsultation).

\section{Perceived ease of use}

While PU refers to consumers' subjective appraisal of a technology performance, perceived ease of use (PEOU) includes the effort side of such an appraisal, encompassing the perceptions of how easy or effortless the use of a given technology may be (Davis, 1989; Davis et al., 1989; Venkatesh, 2000). PEOU influences attitude toward technology adoption both directly and indirectly, through PU. The sense of efficacy and instrumentality are two PEOU mechanisms influencing attitude (Davis et al., 1989). Bandura (1982) points to existing links between efficacy and self-motivation/affect, which can be found in the relationship between PEOU and ATT. Evidences of such positive impact were shown in several studies in the consumer context (Davis, 1993; Davis et al., 1989), including health technology services (Tao et al., 2020).

Regarding indirect impact on ATT, Davis, Bagozzi, and Warshaw (1989) posit that easier to use technologies save consumers' efforts that are redeployed to the actual use of the technology, leading to higher results from this given technology with the same level of efforts. Hence, all the rest being equal, the easier a particular technology may be perceived, the higher the perceptions of its performance or usefulness will be (Kulviwat et al., 2007). Ease of use plays an important role for technology adoption in health services 
(Klaassen, Beijnum, \& Hermens, 2016). In the health patient context, many studies found positive influence of PEOU on $\mathrm{PU}$ and ATT, including the willingness to continue using a fitness app (Beldad \& Hegner, 2018) and the acceptance of telehealth services by older users (Cimperman et al., 2016). Consequently, this study theorizes that:

Hypothesis 5a: Perceived ease of use will have a direct positive impact on patients' attitude in relation to adoption of a technological health service (teleconsultation).

Hypothesis 5b: Perceived ease of use will have a direct positive impact on patients' perceived usefulness of a technological health service (teleconsultation).

\section{Attitude toward adoption and behavioral intention}

Attitude encompasses the evaluative affect from an individual related to his/her willingness to perform a target behavior (Fishbein \& Ajzen, 1975) and is determined by this individual's salient beliefs (Davis et al., 1989). Hence, an individual will tend to adopt a new technology whenever his/ her evaluation process is dominantly positive. The intensity of someone's intention to perform a specific behavior (BI) is influenced not only by the affective (positive or negative) feelings, represented by ATT, but also by cognitive expectations (PU), since performance improvement can be relevant for achieving rewards related to specific consumer activities (Davis et al., 1989).

Kulviwat et al. (2007) highlight the relevance of ATT to understand technology acceptance in consumer context. Evidences of the positive ATT-BI relationship are found in studies about health technological services acceptance as well (Huang, 2013; Lanseng \& Andreassen, 2007; Yun \& Park, 2010). Moreover, despite the ongoing debate about ATT's real relevance to predict BI, the evaluation of 22 trials in health studies suggests that ATT can still be a critical predicting factor to technology acceptance models (Tao et al., 2020).

Finally, due to its reliability to reflect actual use, behavioral intention (BI) has been efficiently adopted as the sole construct to measure technology adoption in several studies (Holden \& Karsh, 2010; Ferreira et al., 2014). In addition, as teleconsultation is still in its incipient introductory phase in Brazil, most study's respondents were still not using this service by the time the data was collected. In such situations, BI gains further reliability as the closest construct to reflect TAM's actual usage (Davis, 1989). Therefore, we utilized BI as the final users' technology acceptance measure in this study.

Hypothesis 6: Attitude toward adoption will have a direct positive impact on patients' behavioral intention to use a technological health service (teleconsultation).

Figure 2 shows the study's proposed model and all its hypotheses.

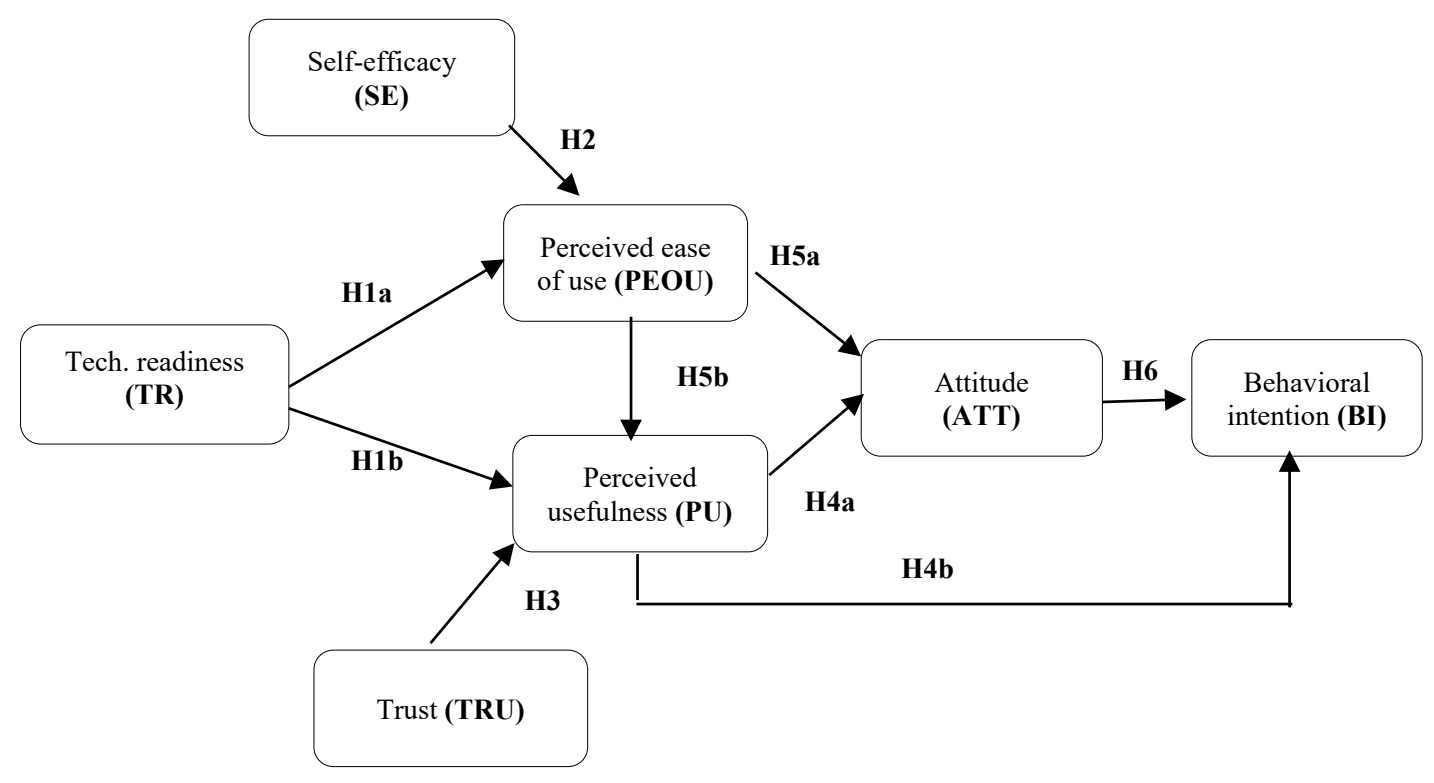

Figure 2. Proposed model with study's hypotheses. 


\section{METHODOLOGY}

This study applied a cross-sectional and structured survey to a non-probabilistic sample of interest. Although the study's selected methods could apply to any technological service in health, teleconsultation was elected due to its relevance in responding to persistent healthcare challenges (e.g., access to continuous quality medical services and health cost reduction), capacity of increasing the medical access to the population, broad applicability, and significance as a potential tool to decrease negative impacts of COVID-19 pandemic related to social distancing (Baudier et al., 2021; Ouimet et al., 2020).

Regarding the latter, teleconsultation can be critical to mitigate the potential transmission of the virus SARSCoV-2, the COVID-19 virus, by promoting the necessary social distancing during the pandemic (Smith et al., 2020). For instance, teleconsultation, among other telehealth services, can provide routine and necessary care access to patients not yet infected, avoiding their exposure to potentially congested health premises (Smith et al., 2020). Teleconsultation can also provide general medical assistance to infected people who must be isolated (Oliveira et al., 2020). Healthcare providers can also minimize their risk of infection by adopting teleconsultation and avoiding direct contact with potentially infected patients (Baudier et al., 2021). In all cases, teleconsultation, as a valuable telehealth service, has already become a strong tool in the response to COVID-19 pandemic (Scott \& Mars, 2020), and has a significant potential to further deliver improved digital health care in the future beyond the current COVID-19 pandemic context (Ouimet et al., 2020).

Additionally, teleconsultation was in the center of a broader debate about telehealth implementation and regulation in Brazil, with several organizations, companies, and providers testing and implementing it after regulatory dispensations approval in April 2020 (Caetano et al., 2020).

\section{Operationalization of variables}

The selection of scales was based on their adherence to the survey's constructs, relevance (scales already developed and tested), and previous empirical application within our scope (health and technology). Therefore, the study used the following scales: Parasuraman and Colby's (2015) TRI 2.0 scale of 16 items for TR; a five-item scale for trust (Velsen et al., 2017); a three-item scale for SE (Sun, Wang, Guo, \& Peng, 2013); a five-item scale for PU (Huang, 2010); a fouritem scale for PEOU (Huang, 2010); and two separate threeitem scales for ATT (Lee, 2005) and BI (Khalifa \& Shen, 2008). All construct-related items were measured by fivepoint Likert scales. Since all scales were originally developed in English, the questionnaire was translated into Portuguese and translated back into English, guaranteeing the scales' integrity. Thirteen additional questions were included to cover demographic characteristics and other general areas of interest. All items were evaluated by marketing or innovation diffusion researchers as well as by a health specialist, both before and after the pre-test process.

The pre-tests included video and phone interviews with potential research respondents aimed at evaluating the clarity and fluidity of the survey's questions. Ten respondents were included in the first pre-test and six additional ones participated in the second pre-test. After each pre-test, the study's researchers assessed together interviewees' inputs and refined the instrument in a consensus-search mode.

At the end, the final instrument, consisting of 52 questions (39 related to the seven constructs' scales and 13 to demographic and other general information), received only minor wording and formatting changes in two demographic and one TR items. All survey's items from each research construct are presented in Appendix A.

\section{Procedures for sampling and data collection}

Since teleconsultation is a general service that could be adopted by any person, the study's population could be the entire society. In line with Tao et al.'s (2020) findings, general consumers and specific patients are both important for studies of technology acceptance in health. Moreover, as teleconsultation was in its primary implementation phase in Brazil, drivers of technology acceptance could come from users' expectations, instead of actual use. Therefore, to enhance the study's final findings, our research used a broad scope for sampling. The main guiding selection principle was the inclusion of respondents who could be responsible for their own choice of the preferred medical care's channels and providers. Thus, the ages of the 415 valid respondents varied from 17 years old (one respondent) to 80 years old (two respondents).

The questionnaires were self-administered and completed electronically. They included a short introductory explanation about the research's purpose and teleconsultation. Respondents' recruiting was performed initially by open and general invitations in social media (e.g., LinkedIn). Only voluntary participation was applied in this research and respondents' anonymity was guaranteed. The survey took place in September 2020.

In total, 527 answers were received. Conditions for validation included the need of $100 \%$ response rate for the 39-construct items as well as other consistency checks, as 
recommended; 415 responses were considered valid for further statistical analyses.

According to valid answers, only $26.7 \%$ of respondents could be classified as regular users of teleconsultation (having experienced the service more than once). From the remaining $73.3 \%$, a total of $19.0 \%$ believed that they could have used teleconsultation once, and the remaining 54.3\% said that they had never used such service before; however, the great majority $(80.0 \%)$ had already heard about it.
Part of the respondents had already been advised by their doctors $(20.0 \%)$ or their health plans $(27.2 \%)$ to use the service. Most respondents believed that teleconsultation should be implemented in Brazil, be it with a limited scope regarding medical specialties $(79.3 \%)$ or only for limited phases of the health treatment $(83.5 \%)$. Answers came from 17 out of 27 Brazilian states. Additional information about the sample group can be found in Table 2 .

Table 2. Sample population's characteristics and other info.

Percentage of respondents

Teleconsultation scope in terms of medical specialties according to respondents:

In all specialties (e.g., psychiatry, pediatrics, pneumology, and all others)

Teleconsultation scope in terms of medical treatment phase according to respondents:

In all phases (e.g., in first consultations, in follow-up consultations, in emergency consultations, and all others) Just in some treatment phases

Main type of health provider used by respondents

National health system (SUS)

Private health plan, using only plan's list of health providers

Private health plan, using services not listed (with further partial or total reimbursement)

Paying directly to service providers

Age
Just in some specialties

In any specialty In any treatment phase

Others

17.8

79.3

2.9

13.9

83.5

2.7

10.2

52.8

25.5

8.3

3.2

9.7

14.4

28.2

30.7

12.7

4.4

Above 65 years old

50.9

49.1

Female

29.0

23.6

29.7

Other state capital city

17.8
Comparing the demographic profiles of the respondents who might have used teleconsultation at least once $(45.7 \%)$ to the ones that had never experienced teleconsultation before $(54.3 \%)$, Table 3 shows that teleconsultation's penetration had only reached the majority of the sample population in four sub-groups of respondents: (a) women (53.5\%); (b) holders of private health plans with reimbursement conditions (51.4\%); 
(c) respondents who search for health services in the city of São Paulo (51.5\%); (d) or in other Brazilian state capitals (56.6\%), except Rio de Janeiro. On the other hand, respondents who (a) pay directly for their health services $(23.5 \%)$, (b) are over 65 years old $(38.9 \%)$, (c) are men (38.7\%), and (d) do not live in Brazilian state capitals $(27.4 \%)$ seem to be more resistant to experiencing teleconsultation so far. Such results suggest that, as predicted in this study's scope, teleconsultation is still at its earlier stages of implementation in Brazil.

Table 3. Use of teleconsultation according to the sample's demographic characteristics.

\begin{tabular}{|c|c|c|}
\hline & $\begin{array}{l}\text { Percentage of respondents who had } \\
\text { used teleconsultation at least once }\end{array}$ & $\begin{array}{l}\text { Percentage of respondents who hac } \\
\text { never used teleconsultation before }\end{array}$ \\
\hline TOTAL & 45.7 & 54.3 \\
\hline \multicolumn{3}{|l|}{ Main type of health provider used by respondents } \\
\hline National health system (SUS) & 42.9 & 57.1 \\
\hline Private health plan, using only plan's list of health providers & 47.5 & 52.5 \\
\hline Private health plan, using services not listed (with further reimbursement) & 51.4 & 48.6 \\
\hline Paying directly to service providers & 23.5 & 76.5 \\
\hline Others & 38.5 & 61.5 \\
\hline \multicolumn{3}{|l|}{ Age } \\
\hline From 17 to 25 years old & 47.5 & 52.5 \\
\hline From 26 to 35 years old & 47.5 & 52.5 \\
\hline From 36 to 45 years old & 46.6 & 53.4 \\
\hline From 46 to 55 years old & 44.4 & 55.6 \\
\hline From 56 to 65 years old & 46.2 & 53.8 \\
\hline Above 65 years old & 38.9 & 61.1 \\
\hline \multicolumn{3}{|l|}{ Gender } \\
\hline Male & 38.7 & 53.5 \\
\hline Female & 61.7 & 46.5 \\
\hline \multicolumn{3}{|l|}{ Preferred cities for use of health services by respondents } \\
\hline Rio de Janeiro & 41.2 & 58.8 \\
\hline São Paulo & 51.5 & 48.5 \\
\hline Other state capital city & 56.6 & 43.4 \\
\hline Not state capital city & 27.4 & 72.6 \\
\hline
\end{tabular}

\section{RESULTS}

\section{Common method variance}

Using information for independent and dependent variables from a single source (the respondents) could generate biases, resulting in common method variance issues. The study applied Harman's one-factor test to investigate such risk (Podsakoff \& Organ, 1986), resulting in eight factors with eigenvalues greater than 1.0 and no single factor being able to explain most of the variance. The factor that better explained the variance corresponded to $28.5 \%$ of the total. Results suggest that common method variance is not a problem for the collected data.

\section{Measurement model}

To test the scales' validity, dimensionality, and reliability, the study employed a confirmatory factor analysis (CFA). Final results, after several iterations for model refining, reached satisfactory fit indexes while maintaining adequate numbers of items per construct, including the maintenance of at least three items per construct. The final 32-item measurement model presented the following indexes: $\chi_{2}=981,617$ and $\mathrm{df}=428(\mathrm{p}<0,001) \mathrm{IFI}=0.934$; $\mathrm{TLI}=0.932 ; \mathrm{CFI}=0.933 ; \mathrm{RMSEA}=0.056$; and $\chi_{2} / \mathrm{df}=$ 2.293 , which suggest adequate fit of the study's proposed model to the collected data (Hair, Black, Babin, \& Anderson, 2009; Hu \& Bentler, 1999). 
Model's face validity was reached by: (a) adopting scales already developed, tested, and used in similar areas of research (health and technology); (b) observing best practices from literature in our translation process; and (c) executing and evaluating two pre-tests before releasing the final instrument. Previous literature review studies in consumer marketing, technology, and health technology predicted positive relationships among constructs.
Table 5 shows positive correlations in all cases, demonstrating nomological validity for the model (Hair et al., 2009). In order to measure variables' fit to model's proposal, convergent validity and reliability were further examined for each construct. Table 4 shows results for composite reliability (CR), average variance extracted (AVE), Cronbach's alpha coefficients, and descriptive statistics (mean and standard deviation).

Table 4. Reliability indexes and descriptive statistics of study's constructs.

\begin{tabular}{|c|c|c|c|c|c|}
\hline & Composite reliability & Cronbach's Alpha & $\begin{array}{c}\text { Average Variance } \\
\text { Extracted }\end{array}$ & MEAN & Standard Deviation \\
\hline Tech. READINESS & 0.91 & 0.71 & 0.50 & 3.29 & 0.55 \\
\hline SELF-EFFICACY & 0.88 & 0.88 & 0.71 & 4.42 & 0.78 \\
\hline TRUST & 0.76 & 0.76 & 0.51 & 3.99 & 0.76 \\
\hline EASE OF USE & 0.89 & 0.89 & 0.68 & 4.29 & 0.80 \\
\hline USEFULNESS & 0.89 & 0.89 & 0.62 & 3.94 & 0.85 \\
\hline ATTITUDE & 0.82 & 0,80 & 0.61 & 3.85 & 0.92 \\
\hline BEHAV. INTENT. & 0.95 & 0.95 & 0.86 & 3.99 & 1.07 \\
\hline
\end{tabular}

Reliability tests for each construct reached the minimum required thresholds (CR and alphas higher than 0.7 ) indicating consistency and reliability among items within each construct (Hair et al., 2009). Regarding convergent validity, all constructs reached the minimal AVE value of 0.5, suggested by Fornell and Larcker (1981).

Latent constructs' discriminant validity was also assessed through the measurement model results. Discriminant validity, referring to how different a construct really is from the others (Hair et al., 2009), was evaluated by analyzing the factor loads of each item, which must be greater in relation to the constructs they are supposed to measure than in relation to other constructs present in the model. The relative importance and significance of the factor loads for each item were interpreted according to the suggestions of Hair, Black, Babin, and Anderson (2009), who state that factor loads greater than 0.3 can be considered significant, greater than 0.4 can considered important, and greater than 0.5 can be considered very significant. All items presented factor loads greater than 0.6 in relation to their respective constructs, suggesting satisfactory discriminant validity. Nevertheless, further testing was carried out, since, according to Fornell and Larcker (1981), constructs achieve discriminant validity when all AVEs are greater than the corresponding squared inter-construct correlations with the other constructs present in the model. Table 5 presents the AVEs for each construct in the main diagonal and the squared correlation coefficients between each pair of constructs in the cells below the main diagonal.

Table 5. Correlations and discriminant validity matrix.

\begin{tabular}{|c|c|c|c|c|c|c|c|}
\hline & $\begin{array}{c}\text { Tech. } \\
\text { READINESS }\end{array}$ & $\begin{array}{c}\text { SELF- } \\
\text { EFFICACY }\end{array}$ & TRUST & EASE OF USE & USEFULNESS & ATTITUDE & $\begin{array}{l}\text { BEHAV. } \\
\text { INTENT. }\end{array}$ \\
\hline $\begin{array}{l}\text { Tech. } \\
\text { READINESS }\end{array}$ & 0.50 & 0.61 & 0.64 & 0.59 & 0.58 & 0.53 & 0.48 \\
\hline SELF-EFFICACY & 0.37 & 0.71 & 0.59 & 0.87 & 0.43 & 0.37 & 0.42 \\
\hline TRUST & 0.41 & 0.34 & 0.51 & 0.57 & 0.69 & 0.68 & 0.61 \\
\hline EASE OF USE & 0.35 & 0.76 & 0.32 & 0.68 & 0.53 & 0.46 & 0.46 \\
\hline USEFULNESS & 0.34 & 0.19 & 0.48 & 0.28 & 0.62 & 0.92 & 0.82 \\
\hline ATTITUDE & 0.28 & 0.14 & 0.46 & 0.21 & 0.85 & 0.61 & 0.84 \\
\hline $\begin{array}{l}\text { BEHAV. } \\
\text { INTENT. }\end{array}$ & 0.23 & 0.18 & 0.37 & 0.21 & 0.68 & 0.70 & 0.86 \\
\hline
\end{tabular}

Note. AVE on diagonal; correlations above and squared correlations below main diagonal. 
The examination of the Table 5 shows that almost all shared variances are lower than the variance extracted by the items measuring the constructs, with the exception of the pairs self-efficacy/ease of use, usefulness/attitude, usefulness/ intention, and attitude/intention. Given those exceptions to Fornell and Larcker's (1981) criteria, we performed an additional test to ensure discriminant validity as indicated by Anderson and Gerbing (1988): for each problematic pair of constructs (SELF/PEOU, PU/ATT, PU/BI, and ATT/ $\mathrm{BI}$ ), we calculated the difference between the original model with correlations allowed to be free and one constrained model that fixed each problematic correlation to unity (i.e., perfectly correlated). Results for all cases showed that statistically significant and lower $\chi_{2}$ values were found for the unconstrained models, providing evidence that discriminant validity was achieved for self-efficacy, ease of use, usefulness, attitude, and behavioral intention.

In sum, after proceeding with validation tests, the model can be considered reliable and ready for study's hypotheses evaluation.

\section{Structural model}

Structural equation modeling (SEM) through the use of the software AMOS was employed to test the proposed model and the study's hypotheses. SEM verifies the fit of the model to the data and the levels of significance for the hypothesized relationships between the study's constructs, attesting their potential veracity or not (Byrne, 2010). The estimation of the model generated indices indicating a good fit to the data: $\chi_{2}=1,214,744$ with $\mathrm{df}=440$, $\chi_{2} / \mathrm{df}$ ratio of $2.76, \mathrm{IFI}=0.91, \mathrm{TLI}=0.90, \mathrm{CFI}=0.91$, and RMSEA = 0.065 (Hair et al., 2009; Hu \& Bentler, 1999).

The authors then verified the path coefficients to test the study's hypotheses in terms of significance, magnitude, and direction (Byrne, 2010). Figure 3 and Table 6 show significance in all hypothesized relationships. Finally, the proportions of the variance explained for each of the four dependent variables of the model were: $47.2 \%$ for usefulness; $67.7 \%$ for behavioral intention, $75.3 \%$ for easy of use; and $84.4 \%$ for attitude.

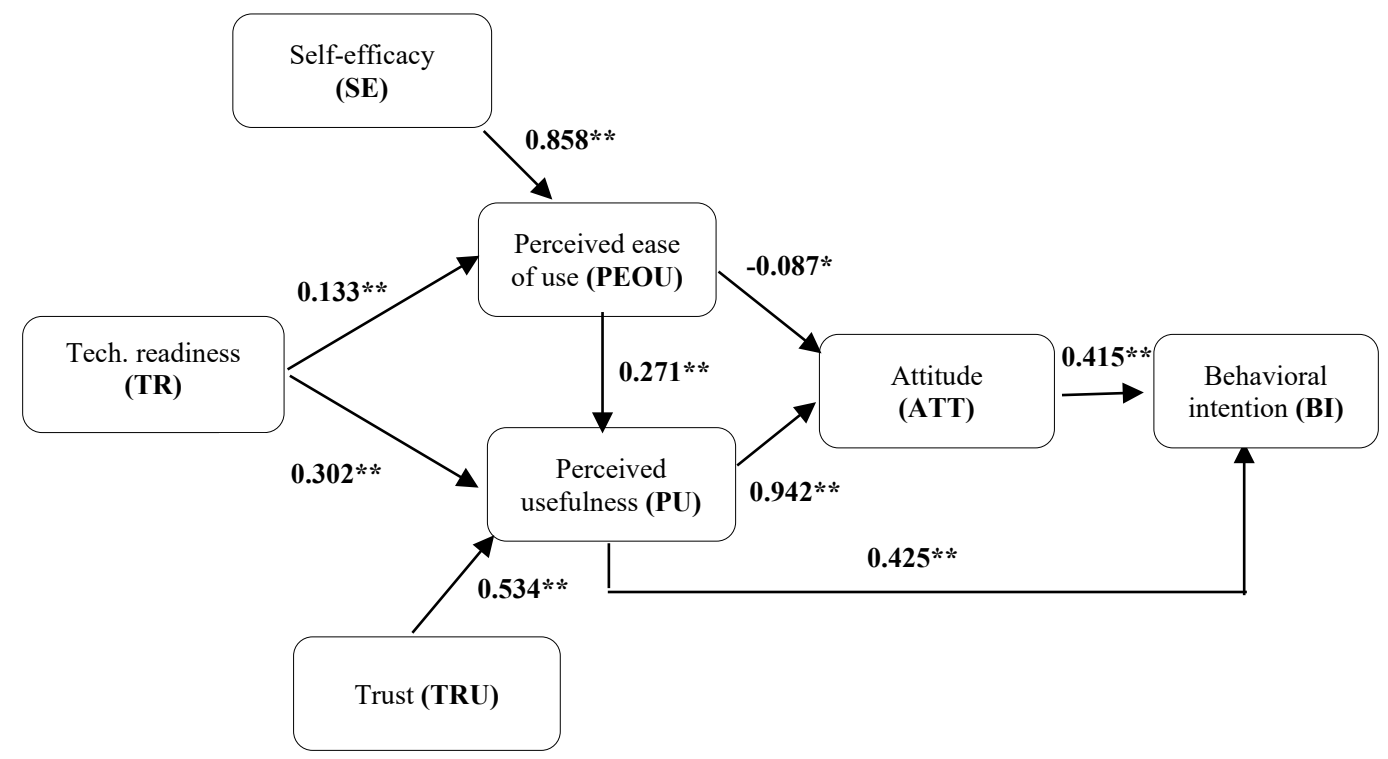

Figure 3. Standardized path coefficients for the study's proposed model $\left({ }^{*} \mathrm{p}<0.05,{ }^{* *} \mathrm{p}<0.01\right)$.

Table 6. Hypotheses, standardized path coefficients, and significances.

\begin{tabular}{|c|c|c|c|}
\hline Path & Standardized Path Coef. & p-Value & Hypothesis supported \\
\hline H1a: Tech. Readiness $\rightarrow$ Perceived Ease of Use & 0.133 & $<0.001$ & yes \\
\hline H1b: Tech. Readiness $\rightarrow$ Usefulness & 0.302 & $<0.001$ & yes \\
\hline H2: Self-efficacy $\rightarrow$ Ease of Use & 0.858 & $<0.001$ & yes \\
\hline H3: Trust $\rightarrow$ Usefulness & 0.534 & $<0.001$ & yes \\
\hline H4a: Usefulness $\rightarrow$ Attitude & 0.942 & $<0.001$ & yes \\
\hline H4b: Usefulness $\rightarrow$ Intention & 0.425 & $<0.001$ & yes \\
\hline H5a: Easy of Use $\rightarrow$ Attitude & -0.087 & 0.022 & no \\
\hline H5b: Easy of Use $\rightarrow$ Usefulness & 0.271 & $<0.001$ & yes \\
\hline H6: Attitude $\rightarrow$ Intention & 0.415 & $<0.001$ & yes \\
\hline
\end{tabular}




\section{DISCUSSION}

Results showed that $67.7 \%$ of teleconsultation acceptance (BI) was captured by the proposed model. Perceived usefulness (PU) and attitude (ATT) had a significant, direct, and positive impact on $\mathrm{BI}$ of 0.425 and 0.415 , respectively. PU shows a slightly higher magnitude on BI compared to ATT (0.425 versus 0.415). PU's high magnitude may indicate the relevance given to the potential impact of such service in consumers' and patients' judgments. Health services, in general, have by their own nature high functional and pragmatic characteristics, since their results can have important impacts on patients' lives (Lanseng \& Andreassen, 2007).

Therefore, a perception of high usefulness of teleconsultation could be associated to the 'rewards' (e.g., higher access to medical services and a solution for the social distancing situation) expected by respondents from the use of such service. Such high level of expected rewards could even compensate any eventual negative attitude toward this technology (Kulviwat et al., 2007). Tao et al. (2020) had also pointed out PU's relevance as an antecedent to BI, suggesting that, in case of regular patients (i.e., patients with previous experience in the use of the researched health technology), PU can often have higher positive magnitude on BI when compared to ATT. In this study, such an outcome could have been influenced not only by the relevance of health services, but also by the COVID-19 context, since the pandemic highlights all health-related issues and, simultaneously, imposes social distancing restrictions creating potential higher propensity for valuating the usefulness of this kind of service by respondents. The positive and high impact from PU on ATT (0.942) reinforces such finding, suggesting high level of rewards expected by respondents from the use of teleconsultation and, thus, driving their attitudes in a positive direction.

PEOU's significant positive impact on PU (0.271) was consistent with literature. However, the estimated coefficient for this relationship $(0.271)$ was lower than the average magnitude of 0.52 found in other studies about consumer acceptance of health information technologies (Tao et al., 2020). Additionally, the low, albeit significant, negative relationship between PEOU and ATT (-0.087) contradicted expected theoretical assumptions. Once more, it seems that due to relevance and the research moment associated with teleconsultation, respondents' acceptance will be related to some pragmatic approach of evaluating service's usefulness, regardless of the technology's easiness to use.

Interestingly, similar findings, such as the lack of relevance from patients' effort expectancy in their intention to use teleconsultation during the COVID-19 pandemic, were suggested by Baudier, Kontradeva, Ammi, Chang, and Schiavone (2021). Such results, along with ours, may reflect that 'exceptional times' may impact patients' behaviors for technology's adoption, by increasing, for instance, the relevance of utilitarian factors over the relevance of other potential natural drivers for technology adoption.

Alternatively, respondents' profile could also have influenced PEOU's results, since it comprehends a fairly young (44 year old average) and potentially highly instructed population (only $10.2 \%$ of respondents used Brazilian public health system and $73.0 \%$ of them pertained to the top two family income levels). As suggested by previous researches, the relevance of PEOU toward technology tends to be higher for older users than for younger (Chien et al., 2019; Fox \& Connolly, 2018). In consequence, the results show that attitude (ATT) is positively driven only by teleconsultation's perceived usefulness (PU), with an opposite and much lower perceived 'user-friendliness' (PEOU) impact.

Due to PU's significant and high impacts on ATT and BI, the comprehension of PU's antecedents (Venkatesh \& Davis, 1996) becomes even more critical to understand teleconsultation acceptance. Results suggested the existence of a significant and positive (0.302) antecedent for PU related to technology readiness (TR), a construct linked to respondents' willingness and beliefs to obtain life improvements from technology (Parasuraman \& Colby, 2015). This may also be influenced by the pandemic context. For instance, from a respondent's perspective, teleconsultation may be considered a potential technological solution for social distancing and health risks associated to the COVID-19 pandemic (Caetano et al., 2020; Oliveira et al., 2020; Scott \& Mars, 2020; Smith et al., 2020). Thus, TR's inclusion in the model strengthened its application in the search of relevant drivers for user' teleconsultation acceptance in Brazil.

In line with theory, trust (TRU) appeared as another relevant antecedent for PU. This might be due to the nature of the service (teleconsultation), since its usefulness depends on patients' willingness to be vulnerable to someone in an 'unbalanced' relationship regarding information and knowledge asymmetries (Velsen et al., 2017). Additionally, the current pandemic scenario may have increased patients' willingness to trust and adopt a sensitive technology without previously experiencing it.

In regard to PEOU's antecedents, results corroborated the literature (Rahimpour et al., 2008; Tsai, 2014; Yun \& Park, 2010), suggesting self-efficacy (SE) is a major driver (0.858) of PEOU for technology acceptance. As suggested by Venkatesh and Davis (1996), both constructs share similarities and, as in the case of teleconsultation, the lack of previous experience with the evaluated technology increases the power of SE in determining consumers' PEOU. In 
addition, and in line with Ferreira, Rocha, and Silva (2014), given that technology readiness reflects individuals' beliefs on how secure and comfortable they would feel in using new technologies, the observed significant positive impact of TR on PEOU (0.133) possibly results from that optimistic point of view in relation to new technologies' complexity. People who believe to have some control over technology tend to find it easier to experiment new technologies, such as teleconsultation (Kuo et al., 2013; Lam et al., 2008).

In sum, results suggest that all model's constructs (PU, ATT, PEOU, TRU, TR, and SE) seem to act as significant drivers for teleconsultation acceptance in Brazil.

\section{CONCLUSIONS}

The use of information and communication technologies (ICT) in health services, such as teleconsultation, can generate several benefits, including efficiency gains, higher accessibility, and decrease of social inequalities (Caetano et al., 2020; Cimperman et al., 2016; Mauco et al., 2019). Nonetheless, teleconsultation was allowed in Brazil only in April 2020, exceptionally, as a consequence of the COVID-19 pandemic. Despite the majority $(73.3 \%)$ of respondents not being able to test regularly the service before this survey, their intention to use (BI) the service averaged 3.99 in a five-point scale, with $68.2 \%$ of respondents grading 4.00 or more, proving general patients' openness to use technological solutions in telemedicine services (Dario et al., 2016).

This research contributed to the theory of technology acceptance by investigating drivers of consumers' teleconsultation acceptance in Brazil. Additionally, the application of the patient's domain in this research, rather than that of the healthcare provider or the organization, contributes to expand theoretical debate on technology acceptance in the health industry (Jennett et al., 2003).

The study confirmed direct and positive effects of PU and ATT on BI (Davis et al., 1989). Although both constructs showed significant results, PU's higher magnitude calls attention to the fact that such high results are usually common only when specific patients have already experienced and developed full understanding of service's benefits (Tao et al., 2020), which is not the case of teleconsultation. Possibly, the potential relevance of teleconsultation for respondents' lives and the specific situation of social distancing experienced during the research may have affected PU's evaluation in this study.

Aimed at investigating potential antecedents to cognitive beliefs (PEOU and PU) in technology acceptance, the study contributed by proposing and testing a model that: (a) confirmed strong influence of trust on
PU, somewhat expected in the specific patient-provider situations of technological health services; (b) confirmed a strong influence of SE on PEOU, also common in this kind of situation in which respondents had to rely on their own SE perceptions as most of them had not experienced the service before (Venkatesh \& Davis, 1996); (c) included and attested technology readiness' influence on PU and PEOU, suggesting that individual traits related to readiness in using any kind of technology can be applied to specific acceptance of technology in health services (teleconsultation).

In sum, in explaining a proportion of $67.7 \%$ of the variance of respondents' BI for teleconsultation through six constructs, the study contributed to a better understanding of drivers of technology acceptance, contemplating idiosyncrasies related to the nature of services with potential high impact on respondents' lives. Additionally, the study's scope (teleconsultation's intention of adoption in Brazil, from a patients' perspective) supports not only the academic debate on technology adoption but also helps the discussion about future introduction of such a relevant service in the country.

Regarding managerial implications, our findings suggest that organizations and providers associated with teleconsultation should pay special attention to consumers' usefulness perceptions of teleconsultation. Acceptance for this service will be mainly impacted by the level of usefulness consumers may perceive in teleconsultation and how capable the technology is in delivering better conditions for health monitoring, convenience, safety, and quality of life improvements.

Clinicians should also observe such patients' needs and attempt to construct an efficient way of fulfilling the desired patients' utilitarian gains (e.g., time saving, safety, and quality care), including some reshaping of these practitioners' current work methods and tools.

In addition, special attention should be granted to antecedents related to these usefulness perceptions. The proposed model showed the relevance of consumers' trust in both the clinicians and the technology associated with teleconsultation, given the level of confidentiality associated to this kind of service. Therefore, healthcare providers should also address the practitioners' intentions to adopt teleconsultation, as it could reflect in the delicate 'trustbased' relationship between clinicians and patients within such new technological boundaries.

On the other hand, until teleconsultation diffusion reaches higher penetration, organizations and providers should foster and search potential users with higher levels of self-efficacy and technology readiness. Teleconsultation seems to be perceived by respondents as necessary; therefore, 
pragmatic use of technology should be prioritized to drive teleconsultation's successful acceptance.

Finally, as mentioned before, our results can be relevant to the upcoming debate on telemedicine in Brazil, including the eventual reconfiguring of health services provided by both private and public stakeholders. Understanding consumers' high valuation of teleconsultation' usefulness and other relevant drivers for its acceptance can foster development of efficient implementation strategies in near future, avoiding resource loses and frustrations, in case telemedicine is allowed in Brazil after the COVID-19 pandemic.

\section{Limitations and future research}

Although respondents' average characteristics may represent a relevant target audience for teleconsultation implementation in Brazil (higher social classes and private health plan consumers), the non-probabilistic process implemented during data collection makes generalization unfeasible. Moreover, only $9.5 \%$ of the sample's population is 60 years old or more, a fact that can be a concern for any health service implementation, given the need to service a growing senior population.

Nonetheless, future research should try to include a longitudinal understanding of the COVID-19 pandemic impact on consumers' acceptance of teleconsultation. This could add value to the debate about the impact of "exceptional times and situations" on the acceptance and diffusion of innovations, mainly from a user perspective. Additionally, other telehealth services could be included in future studies, mainly from countries like Brazil, where telehealth is still in its incipient implementation.

\section{REFERENCES}

Abdullah, F., Ward, R., \& Ahmed, E. (2016) Investigating the influence of the most commonly used external variables of TAM on students' perceived ease of use (PEOU) and perceived usefulness (PU) of e-portfolios. Computers in Human Behavior, 63, 75-90. https://doi.org/10.1016/j.chb.2016.05.014

Adjekum, A., Blasimme, A., \& Vayena, E. (2018). Elements of trust in digital health systems: Scoping review. Journal of Medical Internet Research, 20(12), e11254. https://doi.org/10.2196/11254

Anderson, J. C., \& Gerbing, D. W. (1988). Structural equation modeling in practice: A review and recommended twostep approach. Psychological Bulletin, 103(3), 411-423. https://doi.org/10.1037/0033-2909.103.3.411
Our research's results also showed the relevance of including 'technological' factors in the studies that aim at evaluating the adoption of telehealth solutions from a patient perspective. Thus, future studies can evaluate the inclusion of other potential technological factors in the search for antecedents of patients' propensity to adopt teleconsultation and other telehealth solutions.

In addition, a deeper understanding of the profiles of teleconsultation's users and potential users (e.g., age, income, and other sociodemographic aspects) could help policy makers and providers in directing efficiently their efforts for this service adoption. Moderation studies should investigate the differences that might exist among groups differing in sociodemographic aspects as well as evaluate if groups with different levels of experience with teleconsultation (those who have already used it or those who have only heard of it, for instance) present distinct significances or magnitudes for the relationships proposed in the model. Furthermore, studies evaluating the indirect effects of the proposed antecedents on behavioral intention and the mediating role of attitude and perceived usefulness, while testing out several competing models, could also provide interesting insights on the relationships between the different constructs and patients' intentions to adopt new technologies for health services.

Finally, as tech health services' complexity involves significant participation of diverse stakeholders, acceptance of teleconsultation in Brazil should be observed also by other domains, mainly from the clinicians' point of view, given their primordial role in ICT success adoption in health services.

Bandura, A. (1982). The assessment and predictive generality of self-percepts of efficacy. Journal of Behavior Therapy and Experimental Psychiatry, 13(3), 195-199. https://doi.org/10.1016/0005-7916(82)90004-0

Bashshur, R, Doarn, C. R., Frenk, J. M., Kvedar, J. C., \&Woolliscroft, J. O. (2020). Telemedicine and the COVID-19 pandemic, lessons for the future. Telemedicine and e-Health, 26(5), 571-573. https://doi.org/10.1089/tmj.2020.29040.rb

Baudier, P., Kontradeva, G., Ammi, C., Chang, V., \& Schiavone, F. (2021). Patients' perceptions of teleconsultation during COVID-19: A cross-national study. Technological Forecasting \& Social Change, 163, 120510. https://doi.org/10.1016/j.techfore.2020.120510 
Beldad, A. D., \& Hegner, S. M. (2018). Expanding the technology acceptance model with the inclusion of trust, social influence, and health valuation to determine the predictors of german users' willingness to continue using a fitness app: A structural equation modeling approach. International Journal of Human-Computer Interaction, 34(9), 882-893. https://doi.org/10.1080/10447318.2017.1403220

Byrne, B. M. (2010). Structural equation modeling with AMOS: Basic concepts, applications and programming (2 ed.). New York: Routledge.

Caetano, R., Silva, A. B., Guedes, A. C. C. M., Paiva, C. C. N., Ribeiro, G. R., Santos, D. L., \& Silva, R. M. (2020). Challenges and opportunities for telehealth during the COVID-19 pandemic:Ideas on spaces and initiatives in the Brazilian context. Cadernos de Saúde Pública, 36(5), e00088920. https://doi.org/10.1590/0102-311X00088920

Chauhan, S., \& Jaiswal, M. (2017). A meta-analysis of e-health applications acceptance: Moderating impact of user types and e-health application types. Journal of Enterprise Information Management, 30(2), 295-319. https://doi.org/10.1108/JEIM-08-2015-0078

Chien, S-E., Chu, L., Lee, H.-H., Yang, C.-C., Lin, F.-H., Yang, P.-L., Wang, T.-M., \& Yeh, S.-L. (2019). Age difference in perceived ease of use, curiosity, and implicit negative attitude toward robots. $A C M$ Transactions on Human-Robot Interaction, 8(2), Article 9. https://doi.org/10.1145/3311788

Cilliers, L., Viljoen, K. L.-A., \& Chinyamurindi, W. T. (2018). A study on students' acceptance of mobile phone use to seek health information in South Africa. Health Information Management Journal, 47(2), 59-69. https://doi.org/10.1177/1833358317706185

Cimperman, M., Brencic, M. M., \& Trkman, P. (2016). Analyzing older users' home telehealth services acceptance behavior-applying an Extended UTAUT model. International Journal of Medical Informatics, 90, 22-31. https://doi.org/10.1016/j.ijmedinf.2016.03.002

Compeau, D. R., \& Higgins, C. A. (1995). Computer self-efficacy: Development of a measure and initial test. MIS Quarterly, 19(2), 189-211. https://doi.org/10.2307/249688

Dario, C., Luisotto, E., Pozzo, E. D., Mancin, S., Aletras, V., Newman, S., Gubian, L., \& Saccavini, C. (2016). Assessment of patients' perception of telemedicine services using the service user technology acceptability questionnaire. International Journal of Integrated Care, 16(2), 13. https://doi.org/10.5334/ijic.2219

Davis, F. D. (1989). Perceived usefulness, perceived ease of use, and user acceptance of information technology. MIS Quarterly, 13(3), 319-340. https://doi.org/10.2307/249008

Davis, F. D. (1993). User acceptance of information technology: System characteristics, user perceptions and behavioral impacts. International Journal of Man-Machine Studies, 38(3),475-487.https://doi.org/10.1006/imms.1993.1022

Davis, F. D., Bagozzi, R. P., \& Warshaw, P. R. (1989). User acceptance of computer technology: A comparison of two theoretical models. Management Science, 35(8), 982-1003. Retrieved from https://www.jstor.org/stable/2632151
Dixon, R. F., Zisser, H., Layne, J. E., Barleen, N. A., Miller, D. P., Moloney, D. P., Majithia, A. R., Gabbay, R. A., \& Riff, J. (2020). A virtual type 2 diabetes clinic using continuous glucose monitoring and endocrinology visits. Journal of Diabetes Science and Technology, 14(5), 908-911. https://doi.org/10.1177/1932296819888662

Fanta, G. B., \& Pretorius, L. (2018). A conceptual framework for sustainablee-healthimplementationin resource-constrained settings. South African Journal of Industrial Engineering, 29(3), 132-147. https://dx.doi.org/10.7166/29-3-2055

Ferreira, J. B., Rocha, A., \& Silva, J. F. (2014). Impacts of technology readiness on emotions and cognition in Brazil. Journal of Business Research, 67(5), 865-873. https://doi.org/10.1016/j.jbusres.2013.07.005

Fishbein, M., \& Ajzen, I. (1975). Belief, attitude, intention and behavior: An introduction to theory and research. Reading, MA: Addison-Wesley Publishing.

Fornell, C., \& Larcker, D. F. (1981). Evaluating structural equation models with unobservable variables and measurement error. Journal of Marketing Research, 18(1), 39-50. https://doi.org/10.2307/3151312

Fox, G., \& Connolly, R. (2018). Mobile health technology adoption across generations: Narrowing the digital divide. Information Systems Journal, 28(6), 995-1019. https://doi.org/10.1111/isj.12179

Geffen, D., Karahanna, E., \& Straub, D.W. (2003). Trust and TAM in online shopping: An integrated model. MIS Quarterly, 27(1), 51-90. https://doi.org/10.2307/30036519

Gonçalves, A. A., Martins, C. H. F., Silva, S. L. F. de C., Cheng, C., Santos, R. L. S. dos S., \& Oliveira, S. B. de. (2019). Impactos da implantação da telemedicina no tratamento e prevenção do câncer. Revista Ibérica de Sistemas e Tecnologias de Informação, 17, 222-230. Retrieved from https://www.proquest.com/openview/ f8691ce6ac65f34e990cecf4f3761335/1.pdf?pqorigsite $=$ gscholar $\& \mathrm{cbl}=1006393$

Hair, J. F., Black, W. C., Babin, B. J., \& Anderson, R. E. (2009). Multivariate data analysis (7 ed.). Upper Saddle River: Prentice-Hall.

Hirani, S. P., Rixon, L., Beynon, M., Cartwright, M., Cleanthous, S., Selva, A., Sanders, C., Newman, S. P. (2017). Quantifying beliefs regarding telehealth: Development of the whole systems demonstrator service user technology acceptability questionnaire. Journal of Telemedicine and Telecare, 23(4), 460-469. https://doi.org/10.1177/1357633x16649531

Holden, R. J., \& Karsh, B.-T. (2010). The technology acceptance model: Its past and its future in health care. Journal of Biomedical Informatics, 43(1), 159-172. https://doi.org/10.1016/j.jbi.2009.07.002

Holt, K. A., Karnoe, A., Overgaard, D., Nielsen, S. E., Kayser, L., Roder, M. E., From, G. (2019). Differences in the level of electronic health literacy between users and nonusers of digital health services: An exploratory survey of a group of medical outpatients. Interactive Journal of Medical Research, 8(2), e8423. https://doi.org/10.2196/ijmr.8423 
Hu, L.-T., \& Bentler, P. M. (1999). Cutoff criteria for fit indexes in covariance structure analysis: Conventional criteria versus new alternatives. Structural Equation Modeling, 6(1), 1-55. https://doi.org/10.1080/10705519909540118

Huang, J-C. (2010). Remote health monitoring adoption model based on artificial neural networks. Expert Systems with Applications, 37(1), 307-314. https://doi.org/10.1016/j.eswa.2009.05.063

Huang, J-C. (2013). Innovative health care delivery system-A questionnaire survey to evaluate the influence of behavioral factors on individuals' acceptance of telecare. Computers in Biology and Medicine, 43(4), 281-286. https://doi.org/10.1016/j.compbiomed.2012.12.011

Jennett, P., Jackson, A., Healy, T., Ho, K., Kazanjian, A., Woollard, R., Haydt, S., \& Bates, J. (2003). A study of a rural community's readiness for telehealth. Journal of Telemedicine and Telecare, 9(5), 259-263. https://doi.org/10.1258/135763303769211265

Jones, S. S., Rudin, R. S., Perry, T., \& Shekelle, P. G. (2014). Health information technology: An updated systematic review with a focus on meaningful use. Annals of Internal Medicine, 160(1), 48-54. https://doi.org/10.7326/m13-1531

Kayser, L., Karnoe, A., Furstrand, D., Batterham, R., Christensen, K. B., Elseworth, G., \& Osborne, R. H. (2018). A multidimensional tool based on the ehealth literacy framework: Development and initial validity testing of the ehealth literacy questionnaire (eHLQ). Journal of Medical Internet Research, 20(2), e36. https://doi.org/10.2196/jmir.8371

Kayser, L., Rossen, S., Karnoe, A., Elsworth, G., Vibe-Petersen, J., Christensen, J. F., Ried-Larsen, M., \& Osborne, R. H. (2019). Development of the multidimensional readiness and enablement index for health technology (READHY) tool to measure individuals' health technology readiness: Initial testing in a cancer rehabilitation setting. Journal of Medical Internet Research, 21(2), e10377. https://doi.org/10.2196/10377

Khalifa, M., \& Shen, K. N. (2008). Explaining the adoption of transactional B2C mobile commerce. Journal of Enterprise Information Management, 21(2), 110-124. https://doi.org/10.1108/17410390810851372

Klaassen, B., Beijnum, B. J. F. V., \& Hermens, H. J. (2016). Usability in telemedicine systems - A literature survey. International Journal of Medical Informatics, 93, 57-69. https://doi. org/10.1016/j.ijmedinf.2016.06.004

Kulviwat, S., Bruner, G. C., II, Kumar, A., Nasco, S. A., \& Clark, T. (2007). Toward a unified theory of consumer acceptance technology. Psychology \& Marketing, 24(12), 1059-1084. https://doi.org/10.1002/mar.20196

Kuo, T.-H. (2011). The antecedents of customer relationship in e-banking industry. Journal of Computer Information Systems, 51(3), 57-66. Retrieved from https://www.tandfonline. com/doi/abs/10.1080/08874417.2011.11645486
Kuo, K-M., Liu, C-F., \& Ma, C-C. (2013). An investigation of the effect of nurses' technology readiness on the acceptance of mobile electronic medical record systems. BMC Medical Informatics and Decision Making, 13, 88. https://doi.org/10.1186/1472-6947-13-88

Lam, S. Y., Chiang, J., \& Parasuraman, A. (2008). The effects of the dimensions of technology readiness on technology acceptance: An empirical analysis. Journal of Interactive Marketing,22(4), 19-39.https://doi.org/10.1002/dir.20119

Lanseng, E. J., \& Andreassen, T. W. (2007). Electronic healthcare: A study of people's readiness and attitude toward performing self-diagnosis. International Journal of Service Industry Management, 18(4), 394-417. https://doi.org/10.1108/09564230710778155

Lee, T.-M. (2005). The impact of perceptions of interactivity on customer trust and transaction intentions in mobile commerce. Journal of Electronic Commerce Research, 6(3), $165-180$.

Lin, C-H., Shih, H-Y., \& Sher, P. J. (2007). Integrating technology readiness into technology acceptance: The TRAM Model. Psychology \& Marketing, 24(7), 641-657. https://doi.org/10.1002/mar.20177

Lin, J.-S. C., \& Chang, H.-C. (2011). The role of technology readiness in self-service technology acceptance. Managing Service Quality: An International Journal, 21(4), 424-444. https://doi.org/10.1108/09604521111146289

Malaquias, R. F., \& Hwang, Y. (2016). An empirical study on trust in mobile banking: A developing country perspective. Computers in Human Behavior, 54, 453-461. https://doi.org/10.1016/j.chb.2015.08.039

Mauco, K. L., Scott, R. E., \& Mars, M. (2019). Development of an eHealth readiness assessment framework for Botswana and other developing countries: Interview study. JMIR Medical Informatics, 7(3), e12949. https://doi.org/10.2196\%2F12949

Mayer, R. C., Davis, J. H., \& Schoorman, D. (1995). An integrative model of organizational trust. Academy of Management Review, 20(3), 709-734. https://doi.org/10.2307/258792

Michel-Verkerke, M. B., Stegwee, R. A., \& Spil, T. A. M. (2015). The six P's of the next step in electronic patient records in the Netherlands. Health Policy and Technology, 4(2), 137-143.

Oliveira, W. K., Duarte, E., França, G. V. A., \& Garcia, L. P. (2020). How Brazil can hold back COVID-19. Epidemiologia e Serviços de Saúde, 29(2), e2020044. https://doi.org/10.5123/S1679-49742020000200023

Or, C. K. L., \& Karsh, B.-T. (2009). A systematic review of patient acceptance of consumer health information technology. Journal of the American Medical Informatics Association, 16(4), 550-560. https://doi.org/10.1197/jamia.M2888

Ouimet, A. G., Wagner, G., Raymond, L., \& Pare, G. (2020). Investigating patients' intention to continue using teleconsultation to anticipate postcrisis momentum: Survey study. Journal of Medical Internet Research, 22(11), e22081. https://doi.org/10.2196/22081 
Parasuraman, A. (2000). Technology readiness index (TRI): A multiple-item scale to embrace new technologies. Journal of Service Research, 2(4), 307-320. https://doi.org/10.1177/109467050024001

Parasuraman, A., \& Colby, C. L. (2015). An updated and streamlined technology readiness index: TRI 2.0. Journal of Service Research, 18(1), 59-74. https://doi.org/10.1177/1094670514539730

Podsakoff, P. M., \& Organ, D. W. (1986). Self-reports in organizational research: Problems and prospects. Journal of Management, 12(4), 531-544. https://doi.org/10.1177/014920638601200408

Portnoy, J., Waller, M., \& Elliot, T. (2020). Telemedicine in the era of COVID-19. The Journal of Allergy and Clinical Immunology: In Practice, 8(5), 1489-1491. https://doi.org/10.1016/j.jaip.2020.03.008

Quan, A. M. L., Stiell, I., Perry, J. J., Paradis, M., Brown, E., Gignac, J., Wilson, L., \& Wilson, K. (2020). Mobile clinical decision tools among emergency department clinicians: Web-based survey and analytic data for evaluation of the Ottawa rules app. JMIR MHealth UHealth, 8(1), e15503. https://doi.org/10.2196/15503

Rahimpour, M., Lovell, N. H., Celler, B. G., \& McCormick, J. (2008). Patients' perceptions of a home telecare system. International Journal of Medical Informatics, 77(7), 486498. https://doi.org/10.1016/j.ijmedinf.2007.10.006

Ramírez-Correa, P., Grandón, E. E., Ramírez-Santana, M., \& Órdenes, L. B. (2019). Explaining the use of social network sites as seen by older adults: The enjoyment component of a hedonic information system. International Journal of Environmental Research and Public Health, 16(10), 1673. https://doi.org/10.3390\%2Fijerph16101673

Ratchford, M., \& Barnhart, M. (2012). Development and validation of the technology adoption propensity (TAP) index. Journal of Business Research, 65(8), 1209-1215. https://doi.org/10.1016/j.jbusres.2011.07.001

Reinares-Lara, E., Olarte-Pascual, C., Pelegrín-Borondo, J., \& Pino, G. (2016). Nanoimplants that enhance human capabilities: A cognitive-affective approach to assess individuals' acceptance of this controversial technology. Psychology \& Marketing, 33(9), 704-712. https://doi.org/10.1002/mar.20911

Rogers, E. M. (2003). Diffusion of innovations (5 ed.). New York: Free Press.

Schoorman, F. D., Mayer, R. C., \& Davis, J. H. (2007). An integrative model of organizational trust: Past, present and future. Academy of Management Review, 32(2), 344-354. https://doi.org/10.5465/amr.2007.24348410

Scott, R. E., \& Mars, M. (2020). Response to Smith et al.: Telehealth for global emergencies: Implications for coronavirus disease 2019 (COVID-19). Journal of Telemedicine and Telecare, 26(6), 378-380. https://doi.org/10.1177/1357633X20932416

Sligo, J., Gauld, R., Roberts, V., \& Villa, L. (2017) A literature review for large-scale health information system project planning, implementation and evaluation. International Journal of Medical Informatics, 97, 86-97. https://doi.org/10.1016/j.ijmedinf.2016.09.007
Smith, A. C., Thomas, E., Snoswell, C. L., Haydon, H., Mehrotra, A., Clemensen, J., \& Caffery, L. J. (2020). Telehealth for global emergencies: Implications for coronavirus disease 2019 (COVID-19). Journal of Telemedicine and Telecare, 26(5), 309-313. https://doi.org/10.1177/1357633X20916567

Sun, Y., Wang, N., Guo, X., \& Peng, Z. (2013). Understanding the acceptance of mobile health services: A comparison and integration of alternative models. Journal of Electronic Commerce Research, 14(2), 183-200. Retrieved from http://web.csulb.edu/journals/jecr/issues/20132/paper4. pdf

Tao, D., Wang, T., Wang, T., Zhang, T., Zhang, X., \& Qu, X. (2020). A systematic review and meta-analysis of user acceptance of consumer-oriented health information technologies. Computers in Human Behavior, 104, 106147. https://doi.org/10.1016/j.chb.2019.09.023

Tavares, J., \& Oliveira, T. (2016). Electronic health record patient portal adoption by health care consumers: An acceptance model and survey. Journal of Medical Internet Research, 18(3). https://doi.org/10.2196/jmir.5069

Tsai, C-H. (2014). Integrating social capital theory, social cognitive theory, and the technology acceptance model to explore a behavioral model of telehealth systems. International Journal of Environmental Research and Public Health, 11(5), 49054925. https://doi.org/10.3390\%2Fijerph110504905

Velsen, L. V., Tabak, M., \& Hermens, H. (2017). Measuring patient trust in telemedicine services: Development of a survey instrument and its validation for an anticoagulation webservice. International Journal of Medical Informatics, 97, 52-58. https://doi.org/10.1016/j.ijmedinf.2016.09.009

Venkatesh, V. (2000). Determinants of perceived ease of use: Integrating control, intrinsic motivation, and emotion into the technology acceptance model. Information Systems Research, 11(4), 342-365. Retrieved from https://www.jstor.org/stable/23011042

Venkatesh, V., \& Davis, F. D. (1996). A model of the antecedents of perceived ease of use: Development and test. Decision Sciences, 27(3), 451-481. https://doi.org/10.1111/j.1540-5915.1996.tb00860.x

Yeo, K. J., Al-Ashwal, R. H. A., Handayani, L., \& Lee, S. H. (2019). Healthcare receivers' acceptance of telecardiology in Malaysia. Telkomnika, 17(3), 1128-1135. https://doi.org/10.12928/telkomnika.v17i3.12212

Yosser, I. M., Idrus, Z. B. S. S., \& Ali, A. A. E. (2020). Technology readiness index 2.0 as predictors of e-health readiness among potential users: A case of conflict regions in Libya. Journal of Physics: Conference Series, 1529(3), 032009. https://doi.org/10.1088/1742-6596/1529/3/032009

Yun, E. K., \& Park, H-A. (2010). Consumers' disease information-seeking behaviour on the Internet in Korea. Journal of Clinical Nursing, 19(19-20), 2860-2868. https://doi.org/10.1111/j.1365-2702.2009.03187.x 


\section{Authorship}

\section{Marcus Rodrigues Peixoto*}

Pontifícia Universidade Católica do Rio de Janeiro, IAG Business School

Rua Marquês de São Vicente, n. 225, Gávea, 22451-900, Rio de Janeiro, RJ, Brazil

E-mail address: marcuspeixoto2002@hotmail.com

(D) https://orcid.org/0000-0001-5131-8965

\section{Jorge Brantes Ferreira}

Pontifícia Universidade Católica do Rio de Janeiro, IAG Business School

Rua Marquês de São Vicente, n. 225, Gávea, 22451-900, Rio de Janeiro, RJ, Brazil

E-mail address: jorge.brantes@iag.puc-rio.br

(D) https://orcid.org/0000-0002-9579-4477

\section{Laís Oliveira}

Pontifícia Universidade Católica do Rio de Janeiro, IAG Business School

Rua Marquês de São Vicente, n. 225, Gávea, 22451-900, Rio de Janeiro, RJ, Brazil

E-mail address: 1rdossa@gmail.com

(D) https://orcid.org/0000-0002-1038-7996

* Corresponding Author

\section{Funding}

The authors thank CNPq and FAPERJ for the support and financial resources that made this research possible.

\section{Conflict of Interests}

The authors have stated that there is no conflict of interest.

\section{Copyrights}

RAC owns the copyright to this content.

\section{Plagiarism Check}

The RAC maintains the practice of submitting all documents approved for publication to the plagiarism check, using specific tools, e.g.: iThenticate.

\section{Authors' Contributions}

$1^{\text {st }}$ author: conceptualization (equal); data curation (lead); formal analysis (equal); investigation (lead); methodology (equal); project administration (lead); software (equal); supervision (equal); validation (equal); visualization (lead); writing-original draft (lead); writing-review \& editing (supporting).

$2^{\text {nd }}$ author: conceptualization (equal); formal analysis (equal); methodology (supporting); software (equal); supervision (lead); validation (equal); writing-review \& editing (equal).

$3^{\text {rd }}$ author: conceptualization (supporting); data curation (equal); formal analysis (supporting); investigation (equal); methodology (supporting); project administration (supporting); validation (supporting); visualization (supporting); writing-original draft (supporting); writingreview \& editing (equal).

\section{Peer Review Method}

This content was evaluated using the double-blind peer review process. The disclosure of the reviewers' information on the first page, as well as the Peer Review Report, is made only after concluding the evaluation process, and with the voluntary consent of the respective reviewers and authors.

\section{Data Availability}

All data and materials have been made publicly available through the Harvard Dataverse platform and can be accessed at:

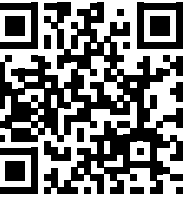

Peixoto, Marcus; Ferreira, Jorge Brantes; Rodrigues, Laís, 2021, "Replication Data for: "Drivers for teleconsultation acceptance in Brazil: patients' perspective during the COVID 19 pandemic." Published by RAC - Revista de Adminstração Contemporânea", Harvard Dataverse, V1. https://doi.org/10.7910/DVN/7QWMSB

RAC encourages data sharing but, in compliance with ethical principles, it does not demand the disclosure of any means of identifying research subjects, preserving the privacy of research subjects. The practice of open data is to enable the reproducibility of results, and to ensure the unrestricted transparency of the results of the published research, without requiring the identity of research subjects. 


\section{APPENDIX A. SCALES USED IN THE RESEARCH}

Technology readiness: based on Parasuraman and Colby's (2015) TRI 2.0 scale of 16 items

1. New technologies contribute to a better quality of life.

2. Technology gives me more freedom of mobility/movement.

3. Technology gives people more control over their daily lives.

4. Technology makes me more productive in my personal life.

5. Other people come to me for advice on new technologies.

6. In general, I am among the first in my circle of friends to acquire new technology when it appears.

7. I can usually figure out new high-tech products and services without help from others.

8. I keep up with the latest technological developments in my areas of interest.

9. When I get technical support from a provider of a high-tech product or service, I sometimes feel as if I am being taken advantage of by someone who knows more than I do.

10. Technical support lines (by telephone or internet) are not helpful because they don't explain things in terms I understand.

11. Sometimes, I think that technology systems are not designed for use by ordinary people.

12. There is no such thing as a manual for a high-tech product or service that's written in plain language.

13. People are too dependent on technology to do things for them.

14. Too much technology distracts people to a point that is harmful.

15. Technology lowers the quality of relationships by reducing personal interaction.

16. I do not feel confident doing business with a place that can only be reached online.

Trust: based on the five-item scale for trust (Velsen et al., 2017)

1. I could trust the site used for my teleconsultation.

2. I could trust that possible problems with the site used for my teleconsultation will be solved properly.

3. I could trust the service of teleconsultation less than other online services, such as Amazon.com and the website of my municipality.

4. I could feel at ease when working with the site used for my teleconsultation.

5. I may not like to enter my personal data on the site used for my teleconsultation.

Self-efficacy: from the three-item scale for SE (Sun et al., 2013)

1. It would be easy for me to use teleconsultation services.

2. I would have the capability to use teleconsultation services.

3. I would be able to use teleconsultation services without much effort.

Perceived usefulness: from Huang's (2010) five-item scale

1. I find that using teleconsultation services would be helpful in monitoring my health.

2. I find that using teleconsultation services would make me feel safer in my daily life.

3. Teleconsultation services could enhance the level of convenience in accessing medical care services.

4. Teleconsultation services could enhance the quality of my life.

5. Overall, I find that teleconsultation services would be highly useful. 
Perceived ease of use: Huang's (2010) four-item scale

1. I find that using teleconsultation services would be simple.

2. I find that using teleconsultation services would be easy to learn.

3. I find that teleconsultation services would be easily understandable and clear for me.

4. Overall, I find that using teleconsultation services would be convenient.

Attitude: adapted from Lee's (2005) three-item scale

1. Using teleconsultation services for accessing medical care is a good idea.

2. Using teleconsultation services for accessing medical care is a wise idea.

3. Using teleconsultation services for accessing medical care is an appealing idea.

Behavioral intention: adapted from Khalifa and Shen's (2008) three-item scale

1. I intend to use teleconsultation services in the near future.

2. It is likely that I will use teleconsultation services in the near future.

3. I expect to use teleconsultation services in the near future. 